\title{
Opiniães
}

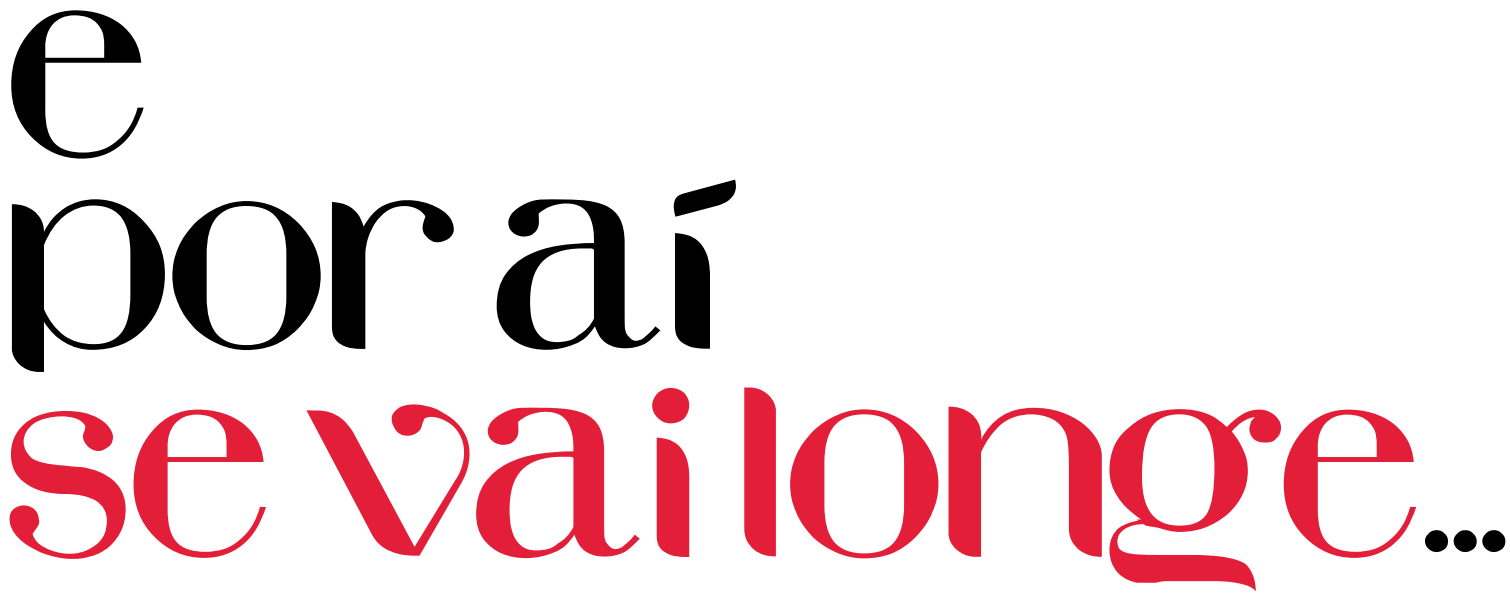

\section{Betina Leme*}

Graduada em Psicologia (IP-USP) e Letras-Português e Linguística (FFLCH-USP), mestranda no Programa de Pós-Graduação em Literatura Brasileira (DLCV-FFLCH-USP). Bolsista CNPq. E-mail para contato: betina. leme@gmail.com
O número 11 da Opiniães vem enxuto:

- Oito artigos, assim divididos: (quatro) Dossiê Autores-Editores e (quatro) artigos de tema livre em literatura brasileira.

- Uma entrevista.

- Doze poemas e um conto, acompanhado de um breve artigo crítico.

Do DOSSIÊ, dedicado ao tema AUTORES-EDITORES, deixaremos aqui registrada parte da chamada, tal como foi divulgada na ocasião, na qual está descrito o que entendemos por autores-editores e que tipo de questão se propunha que os artigos abordassem: 


\begin{abstract}
Autores de literatura brasileira que - reconhecidamente, indiscutivelmente e em primeiro lugar autores - se dedica[ra]m em algum momento da vida também ao ofício de editores ou desempenha[ra]m funções editoriais relacionadas a suas próprias publicações (livros, revistas etc.) ou às de outrem. Podemos dizer que suas atividades, tanto no campo editorial como no campo literário, possuem características pertinentes à dupla vocação de autores e editores? O que resulta da confluência dessas esferas, consideradas complementares por alguns e incompatíveis por outros tantos? Qual foi/é o impacto de tal confluência para a literatura brasileira? As transformações pelas quais têm passado a literatura e o mercado editorial ao longo do tempo afeta[ra]m de alguma maneira as relações aqui aventadas? Artigos que abordem de algum modo as questões propostas nesta chamada ou que as tangenciem de maneira significativa para aprofundar e ampliar o debate e a reflexão propostos são bem-vindos.
\end{abstract}

Os quatro artigos que agora publicamos no dossiê, embora poucos, trazem contribuições muito bem-vindas ao debate e à reflexão sobre o tema. Durante o processo de edição da revista, foi se delineando a percepção de que, embora presente desde há muito na história da literatura, a figura do autor-editor foi pouco debatida, até o momento, nesses termos aqui propostos. Assim, ao lançarmos a chamada para o dossiê, apesar do grande interesse demonstrado por aqueles que dela tomavam conhecimento, poucos foram os artigos submetidos à revista. $E$, dentre estes, nem todos foram aceitos para publicação na etapa de avaliação pelos pares. (Esperamos sinceramente que os autores cujos textos não foram publicados não deixem de lado a ideia de aprimorar e aprofundar o debate.)
Provavelmente Monteiro Lobato seja o brasileiro mais conhecido e estudado dentro dessa especificidade de autor-editor, e tal fato se refletiu neste dossiê: dos quatro artigos que o compõem, dois envolvem o Monteiro Lobato editor.

Em "'Que obra preciosa estás a fazer!' - Considerações sobre as cartas do editor Monteiro Lobato ao escritor Lima Barreto", Emerson Tin apresenta cuidadosa reflexão sobre essa relação que se deu exclusivamente por meio da troca de cartas (Lima e Lobato nunca chegaram a se encontrar pessoalmente), além de debater com e discordar em vários aspectos de outro artigo existente sobre "A correspondência entre Lima Barreto e Monteiro Lobato", de Antonio Arnoni Prado. Camila Russo de Almeida Spagnoli, por sua vez, traz a relação entre o editor Lobato e o amigo escritor Godofredo Rangel, em "Monteiro Lobato publica Godofredo Rangel".

Interessante observar que os dois artigos acabaram por se mostrar complementares, a leitura de um acrescentando em muito à leitura do outro. Exemplo disso é a comparação que se pode fazer entre o comportamento de Lobato com relação a Ferdinando Borba, no primeiro artigo, e a Graça Aranha, no segundo, e que nos mostra que havia coerência no comportamento do editor.

Quanto ao artigo de Bruna Letícia Pinheiro Carmelin e Ulisses Infante sobre o Graciliano Ramos leitor de Guimarães Rosa, embora aquele não tenha efetivamente editado este, a figura do autor-editor se faz presente na situação toda e justifica sua entrada neste dossiê. É interessante lembrar que Graciliano Ramos foi, ele mesmo, "descoberto" e editado pela primeira vez por um autor-editor: Augusto Frederico Schmidt (infelizmente ausente neste dossiê, como tantos outros autores-editores que aguardam, ainda, que o tema ultrapasse a fase de latência e passe à de produção acadêmica). Embora não tenha sido efetivamente editor 
de Guimarães Rosa, Graciliano comportou-se como um, e muitas de suas ações resultaram em fatos concretos que podem ser compreendidos como produtos da ação de um editor. Sem spoilers aqui: basta ler o artigo para entender.

O artigo de Carlos Cortez Minchillo, que arremata o dossiê, reflete sobre a integração entre as experiências de autor e editor em Erico Verissimo, ao mesmo tempo que debate aspectos vinculados à presença de Verissimo no cenário internacional, como "trânsito intercultural de livros" e "política de tradução".

Tanto Carlos Cortez Minchillo como Emerson Tin foram instigados, por esta editora, a enviar artigos para o Dossiê. Tal fato assim se deu porque, ao pesquisar sobre o tema - (e aqui devo fazer uma pausa para agradecer especialmente a dica preciosa de Luiza Franco Moreira) -, encontrei, na produção acadêmica de ambos, material em que a reflexão sobre a figura do autor-editor estava já avançada, embora não houvesse, ainda, a produção de artigos específicos tais como estes com os quais somos agora presenteados. Deixo aqui meus sinceros agradecimentos, a ambos, por aceitarem o convite/desafio.

As ausências, neste dossiê, são incontáveis, e nos dizem do quanto esse tema está presente na literatura brasileira - e na literatura em geral - e pede que lhe seja dada maior atenção. A começar pelas revistas literárias, que são um antro de autores editores desde sempre - Álvares de Azevedo e a Revista Mensal da Sociedade Ensaio Filosófico Paulistano, fundada em 1851, os Andrades modernistas Mário, Oswald, Drummond... e, numa linha temporal contínua e recheada de títulos, aquela revista que acaba de ser lançada hoje mesmo quando se lê esta linha. Além de nomes como Augusto Frederico Schmidt, João Cabral de Melo Neto, Fernando Sabino, os concretos, Ana Cristina Cesar e o pessoal todo da Geração Mimeógrafo, e por aí se vai longe...

A Parte II da Opiniães apresenta quatro artigos de tema livre em literatura brasileira, dos autores Jéssica Casarin, larima Nunes Redu, Gabriel Queiroz Guimarães Hernandez, Jean Fabricio Lopes Ferreira e Andrea Czarnobay Perrot. Todos eles, de acordo com os padrões editoriais da Opiniães, atualizam de alguma maneira o debate dentro do que se propõem a tratar. Nessa seção, a heterogeneidade é a regra.

Na Parte III, a entrevista de Luciano Jesus Gonçalves com André Sefrin sobre o autor Samuel Rawet provoca impulsos de sair em busca de algum dos livros do autor e começar a lê-lo imediatamente. Para quem já o conhece, também há novidades.

Na parte IV, literatura concentrada. É ir lá e ler. Agradeço a Simone Guimarães e Luis Eduardo de Sousa, instigados insistentemente por esta editora a enviar seus poemas, pois era imperioso publicá-los. André Luiz do Amaral e Diana Menasché completam o quarteto de poetas, tornando-o harmonioso. Na prosa, "Coisa", do autor-editor Enrique Andres de Oliveira Aue, prende a atenção do leitor até o fim, vencendo- " "por forfait", nas palavras de João Bense, autor do breve artigo crítico que acompanha o conto.

Boa leitura. 